\title{
O trabalho como fator determinante da defasagem escolar dos meninos no Brasil: mito ou realidade?*
}

\author{
Amélia Cristina Abreu Artes** \\ Marília Pinto de Carvalho***
}

\begin{abstract}
Resumo
Este artigo tem por objetivo avaliar a influência do trabalho nas trajetórias escolares a partir dos microdados da Pesquisa Nacional de Amostra por Domicílio - PNAD 2006. Desenvolve-se uma modelagem estatística, visando explicar a defasagem entre idade $e$ anos de estudo a partir da variável sexo e considerando o fator trabalho como variável de controle. Os resultados indicam que o trabalho prejudica o percurso escolar mais intensamente para os meninos e os afazeres domésticos de forma mais sutil para as meninas, com resultados piores para os negros de ambos os sexos, mas somente essa variável não explica a maior defasagem escolar do sexo masculino.
\end{abstract}

Palauras-chave: Gênero, Trabalho Infanto-juvenil, Defasagem Escolar, Meninos, Masculinidade.

\footnotetext{
" Recebido para publicação em março de 2010, aceito em maio de 2010. Este artigo apresenta parte dos resultados da tese de doutorado de Amélia Cristina Abreu Artes, defendido em 2009 na Faculdade de Educação da USP, sob orientação de Marilia Pinto de Carvalho.

** Doutora em Educação, professora na Universidade Bandeirante de São Paulo. a.artes@uol.com.br

**** Professora Livre Docente na Faculdade de Educação da Universidade de São Paulo.mariliac@usp.br
}

cadernos pagu (34), janeiro-junho de 2010:41-74. 
Defasagem escolar dos meninos no Brasil

Labor as a Determinant Factor of School Result Discrepancy in Brazil: Myth or Reality?

\begin{abstract}
This article aims to evaluate the labor influence on school courses of boys and girls. Based on the micro data of PNAD 2006 (National Residence Sample Survey), a statistic model is developed to explain the discrepancy in age- years of study, taking into account the sex and considering labor as a control variable. The results indicate that working damages more intensively the boys' school process, and housework in a more subtle way influences the girls' school process. The worse results were observed for blacks of both sex.
\end{abstract}

Key Words: Gender, Child and Adolescent Labor, Age-Grade Discrepancy, Boys, Masculinity. 
Dados internacionais mostram que, em países pobres e em desenvolvimento, localizados predominantemente no Continente Africano e no sudoeste da Ásia, a escolarização das meninas apresenta piores indicadores que a dos meninos (Relatório de Monitoramente Global - RMG, UNESCO, 2004). Porém, ao analisar a realidade educacional brasileira e latino-americana, as diferenças educacionais são favoráveis às meninas (entre outros, ver Carvalho, 2001; Rosemberg, 1990; Ferraro, 2006).

Uma das explicações frequentemente aventadas, quando se observa essas trajetórias escolares mais tumultuadas dos meninos e rapazes no Brasil, é o fato de terem maior presença no mundo do trabalho (Kassouf, 2007; Rocha, 2003; Schwartzman, 2004). Mas seria esta a única ou principal explicação para o pior desempenho escolar dos meninos? Não haveria outros fatores?

Este artigo explora os dados da Pesquisa Nacional por Amostra de Domicílios - PNAD 2006, a partir das informações sobre defasagem entre idade e anos de estudo, utilizadas como indicador do percurso escolar, comparando meninos e meninas na faixa etária entre 10 e 14 anos. A escolha por um indicador de eficiência e rendimento se deve à valorização que se pretende dar às trajetórias de escolarização. A base de dados da PNAD apresenta como variável derivada os anos de estudo da população, utilizada também por Ferraro (2002, 2007a, 2007b). ${ }^{1}$

Perceber os meninos em uma condição desfavorável, comparado às meninas, exige uma postura teórica capaz de ir além de idéias pré-estabelecidas, uma vez que o conceito de gênero construiu-se a partir do movimento feminista, que procurava dar visibilidade às mulheres na busca pela igualdade de direitos e condições, ressaltando as relações de poder (Rosemberg,

1 Esta defasagem pode ser medida no intervalo de um ano ou mais. Algumas publicações adotam a defasagem de um ano, como o Dicionário de Indicadores Educacionais MEC/INEP (2004), porém, como o sistema de ensino brasileiro permite o ingresso no primeiro ano de escolarização obrigatória com a idade completa ou a completar, decidiu-se que, para a construção do indicador, fosse considerado um atraso de dois anos. 
Defasagem escolar dos meninos no Brasil

2002). Se o conceito de gênero que embasa esta análise procura se afastar de uma compreensão biológica, entendendo que as diferenças observadas entre meninos e meninas têm como origem as construções sociais de masculinidades e feminilidades, historicamente definidas (Scott, 1995), essa abordagem questiona também uma visão bipolar dos sexos, que passam a ser vistos como blocos não homogêneos internamente. Segundo Carvalho (1999:32), "a polaridade excludente ou a oposição binária não é a única forma de apreender a diferença, e nem a ênfase na diferença a única maneira de perceber homens e mulheres".

Isso nos permitiu indagar quais meninos e rapazes vão mal na escola. Nesse sentido, buscamos fracionar os grupos de cada sexo, indicando como outras variáveis intervêm conjuntamente na produção dos resultados escolares de sucesso para as meninas.

Assim colocado, não se pode dizer que haja indicadores de gênero, mas sim de sexo, já que as pesquisas quantitativas referem-se ao sexo do respondente (ou sujeito), e não a seu lugar social, isto é, seu lugar nas relações de gênero. Dessa forma, a variável utilizada neste estudo é o sexo dos sujeitos e o gênero será utilizado como categoria de análise para ajudar a explicar as diferenças encontradas no desempenho escolar de meninos e meninas.

Optamos por trabalhar com a faixa etária de 10 a 14 anos, que corresponde ao período final do ensino fundamental ${ }^{2}$, utilizando as informações disponíveis no questionário da PNAD.

Além de cada uma das idades, esse grupo foi fracionado, em primeiro lugar, considerando as desigualdades sociais $e$ econômicas entre as regiões do país. Se os estudos internacionais demonstram que, nas regiões pobres do mundo, as meninas são as mais prejudicadas no acesso à educação (RMG, UNESCO, 2004), seria essa realidade a mesma no Brasil? Aparentemente, não. Os

2 A idade prevista para frequência ao ensino fundamental foi modificada pela Lei 11274/06, que institui o ensino fundamental de nove anos, com ingresso aos seis anos. Como este estudo trabalha com dados da PNAD 2006, a modificação não atinge as análises. 
estudos de Beltrão (2002) e Ferraro $(2007,2009)$ indicam que, nas regiões mais pobres do país, a diferença de desempenho escolar a favor das meninas é mais acentuada do que nas regiões mais ricas. A fim de considerar esses aspectos, agrupamos as 27 Unidades da Federação de acordo com seus IDH (Índice de Desenvolvimento Humano) em três grupos: alto (superior a 0,773), médio (entre 0,713 e 0,773) e baixo (inferior a 0,705). ${ }^{3}$

Em segundo lugar, consideramos também a variável cor/raça que é apresentada ao entrevistado na PNAD segundo as categorias utilizadas pelo IBGE (branca, preta, parda, amarela $e$ indígena). Neste artigo, o conceito de raça é utilizado como categoria sociológica e política - portanto, não biológica -, conforme descrito por Costa (2002), e os dados foram organizados da seguinte forma: brancos $^{4} e$ negros (incluindo os pretos $e$ pardos).

\section{Meninos, meninas e o trabalho}

Frequentemente visto sob uma ótica negativa, o "trabalho infanto-juvenil" tem sido considerado como o principal responsável pelo mau desempenho escolar, principalmente dos meninos, explicação encontrada tanto no senso comum quanto em diversos textos acadêmicos. $\mathrm{E}$ isso porque os meninos não apenas entrariam no mundo do trabalho com maior freqüencia $e$ mais cedo que as meninas, mas também cumpririam tarefas que, muitas vezes, impossibilitariam estar na escola. Em 2006, segundo o IBGE, na faixa etária de 5 a 17 anos, $11,5 \%$ das crianças trabalhavam, totalizando 5,1 milhões, entre os quais havia uma predominância de meninos (na faixa etária dos 10 aos 13 anos, por exemplo, 10,5\% dos meninos e 5,8\% das meninas estavam ocupados). No caso das meninas, não haveria prejuízo à

3 Fonte: Atlas de Desenvolvimento no Brasil, 2000.

${ }^{4}$ No estudo, foram desconsiderados os indígenas e os amarelos, que representam $0.3 \%$ do total da população e cujas especificidades demandariam análise à parte. 
Defasagem escolar dos meninos no Brasil

escolarização, pois elas estariam inseridas principalmente em atividades domésticas que, aparentemente, melhor se adequariam às demandas escolares, em razão principalmente da flexibilidade de horários (RMG, 2004, UNESCO).

Ao considerar no estudo a variável trabalho, portanto, é necessário explorar suas diferentes dimensões. Afinal, que tipo de trabalho é exercido por meninos e meninas? Como a flexibilidade $e$ a precariedade das relações de trabalho atingem cada sexo? Não são as atividades domésticas uma modalidade de trabalho, porém não remunerada?

Neste artigo, os "afazeres domésticos" estão alçados à categoria de atividade, com o mesmo status que o trabalho, buscando romper com a aparente neutralidade dessa categoria $e$ tornando-a uma "categoria sexuada" (Hirata, 2002), uma vez que as atividades domésticas são exercidas principalmente por mulheres e associadas à feminilidade: no Brasil, em 2007, 89,9\% das mulheres com 16 anos ou mais afirmavam cuidar de afazeres domésticos e somente $50,7 \%$ dos homens o faziam (Pinheiro et alii, 2008). "Estas diferenças são reproduzidas nas áreas urbanas e nas áreas rurais, entre brancos/as e entre negros/as, além de atravessarem todas as regiões do país" (Id. ib:35). Além disso, enquanto as mulheres dedicavam, em média, 27,2 horas por semana a essas atividades, os homens dedicavam 10,6 horas, o que representa quase três vezes menos. Bruschini (2006) analisa o trabalho doméstico como inatividade econômica, ou trabalho não remunerado. Segundo a autora, na faixa etária dos 10 aos 14 anos, as meninas gastavam aproximadamente 14 horas semanais em afazeres domésticos enquanto os meninos disponibilizavam menos de 9 horas. Mantivemos a denominação "afazeres domésticos" por ser utilizada nos dados da PNAD.

Assim, da mesma forma que é importante caracterizar o tipo de trabalho desenvolvido por meninos e meninas, o mesmo se

5 O termo "trabalho" utilizado aqui inclui o exercício de tarefas remuneradas no mercado informal e formal, dentro ou fora do domicílio. 
deve fazer com relação aos afazeres domésticos: as atividades domésticas realizadas por homens e mulheres seriam diferentes? Quanto tempo cada um desses grupos gastaria para executá-las? Se os meninos estão mais presentes no trabalho, estariam as meninas mais presentes nos afazeres domésticos? Qual o prejuízo de cada atividade nos resultados escolares?

Se poucos são os estudos que diferenciam, por sexo, as trajetórias escolares associadas à inserção no mercado de trabalho, mais raros ainda são os que consideram os afazeres domésticos nessa questão. Observamos que, enquanto uma pequena parcela de jovens da faixa etária escolhida trabalha $10,6 \%$ dos meninos e 5,8\% das meninas -, a atividade afazeres domésticos é realizada por $47 \%$ dos meninos e $78 \%$ das meninas (PNAD 2006), com diferenças significativas entre o tempo despendido por sexo.

\section{Análise descritiva - PNAD 2006 - 10 a 14 anos}

Na faixa etária de 10 a 14 anos foram computados 39.459 sujeitos na amostra, sendo 50,9\% homens e 49,1\% mulheres. Para as análises apresentadas, a amostra foi expandida para toda a população brasileira ${ }^{6}$, totalizando 9.017 .494 meninos e 8.684.667 meninas. Para facilitar a visualização das tabelas, optamos por apresentar as informações apenas em suas porcentagens.

$\mathrm{O}$ índice de negros (soma de pretos e pardos) supera o de brancos, em ambos os sexos, compondo $56,1 \%$ dos homens $e$ $55,3 \%$ das mulheres.

A freqüência à escola é mais presente no universo feminino e diminui com a idade. Enquanto aos 10 anos $99,1 \%$ das meninas e $98,4 \%$ dos meninos frequentam a escola, este índice diminui para $94,1 \%$ e $93,6 \%$, respectivamente, aos 14 anos. No total, estão

${ }^{6}$ Foram verificadas algumas tabelas de acordo com as disponibilizadas no site do IBGE, encontrando resultados coerentes.

www.ibge.gov.br/home/estatistica/população/trabalhadoreserendimento/pnad200 6/tabbrasil.shtm 
Defasagem escolar dos meninos no Brasil

fora da escola 266.675 meninos (3\%) e 214.440 meninas (2,5\%). O cruzamento de informações a respeito de trabalho e frequência à escola demonstra que a maior parte dos jovens consegue conciliar as duas atividades. Já a atividade afazeres domésticos está claramente associada ao universo das meninas: 78,8\% delas, contra 45,8\% dos meninos, realizam-na associada à freqüência a escola.

Uma parcela significativa dos jovens que não estudam também estão fora do mundo do trabalho: $28,7 \%$ dos meninos $e$ $11,7 \%$ das meninas. Se o trabalho é apresentado como a principal justificativa para o abandono escolar, como explicar, então, que mais de 76 mil rapazes não frequentam a escola e não trabalham? Teriam esses jovens abandonado a escola para procurar emprego, ou outras circunstâncias estariam afastando-os desses dois universos?

A tabela $1^{7}$ apresenta a defasagem idade/anos de estudo por idade, sinalizando que o índice de defasagem aumenta proporcionalmente à idade. Nota-se também que a defasagem é maior para os meninos e que a diferença se mantém com o aumento da idade. De forma geral, nessa faixa etária, $52,5 \%$ dos meninos e $41,7 \%$ das meninas estão defasados.

7 Para a apresentação da relação entre cada uma das variáveis utilizadas e a defasagem escolar - definida a partir da relação entre idade e anos de estudo as tabelas seguintes são organizadas em duas partes. As primeiras duas colunas apresentam a porcentagem de defasados dentro da variável escolhida (idade, raça, IDH, trabalho e afazeres domésticos), totalizando $100 \%$ da população; a terceira e quarta colunas apresentam a porcentagem dentro da variável defasagem, não permitindo a totalização na vertical. Na última linha dessas colunas, é apresentada a distribuição percentual de defasados por sexo. 
Amélia Artes e Marilia Carvalho

Tabela 1

Defasagem idade/anos de estudo, por sexo e idade (10 a 14 anos)

\begin{tabular}{ccccc}
\hline & \multicolumn{2}{c}{$\begin{array}{c}\text { Distribuição etária de } \\
\text { defasados por sexo }(\%)\end{array}$} & \multicolumn{2}{c}{$\begin{array}{c}\text { Proporção de defasados } \\
\text { por faixa etária para cada } \\
\text { sexo }(\%)\end{array}$} \\
\hline Idade & homens & mulheres & homens & mulheres \\
\hline 10 anos & 16 & 15 & 41,4 & 33 \\
\hline 11 anos & 18 & 17,6 & 46,2 & 36,6 \\
\hline 12 anos & 21 & 20,1 & 53,7 & 41,3 \\
\hline 13 anos & 21,6 & 22,3 & 58,2 & 46,7 \\
\hline 14 anos & 23,4 & 24,2 & 63,7 & 53 \\
\hline total & 100 & 100 & 52,5 & 41,7 \\
\hline
\end{tabular}

Fonte: Microdados PNAD 2006

As colunas à direita da tabela mostram que a diferença entre meninos e meninas defasados, que aumenta com a idade, é constante e desfavorável aos meninos.

A tabela 2 revela os resultados para a relação entre defasagem idade/anos de estudo e raça. Considerada a população pesquisada, tem-se para essa faixa etária: $43,9 \%$ de meninos brancos e $56,1 \%$ de negros; $44,7 \%$ de meninas brancas e $55,3 \%$ de meninas negras. Ao acrescentar o indicador de defasagem, esses índices modificam-se: $39,7 \%$ dos meninos brancos estão defasados, contra $62,5 \%$ dos negros. Essa diferença é menor no caso das meninas: $32,4 \%$ das meninas brancas estão defasadas, contra 49,3\% das negras. Esses resultados reforçam a importância da raça na produção da defasagem, acentuada pela pertença ao sexo masculino, nosso foco de análise. 
Defasagem escolar dos meninos no Brasil

Tabela 2

Defasagem idade/anos de estudo, por sexo e raça (10 a 14 anos)

\begin{tabular}{lcccc}
\hline & \multicolumn{2}{c}{$\begin{array}{c}\text { Distribuição por raça de } \\
\text { defasados por sexo (\%) }\end{array}$} & \multicolumn{2}{c}{$\begin{array}{c}\text { Proporção de defasados por } \\
\text { raça para cada sexo (\%) }\end{array}$} \\
\hline raça & homens & mulheres & homens & mulheres \\
\hline branco & 33.2 & 34,7 & 39,7 & 32,4 \\
\hline negro & 66,8 & 65,3 & 62,5 & 49,3 \\
\hline total & 100 & 100 & 52,5 & 41,7 \\
\hline
\end{tabular}

Fonte: Microdados PNAD 2006

A tabela 3 apresenta a distribuição por IDH. À direita, observa-se que a defasagem é maior para ambos os sexos nas Unidades da Federação (UF) com IDH mais baixo. Ao mesmo tempo, a diferença entre as defasagens masculina e feminina também é maior nestas regiões, reforçando a tese de que nas áreas mais pobres do país os meninos apresentam os piores percursos escolares.

Tabela 3

Defasagem idade / anos de estudo, por sexo e IDH (10 a 14 anos)

\begin{tabular}{ccccc}
\hline & \multicolumn{2}{c}{$\begin{array}{c}\text { Distribuição por IDH de } \\
\text { defasados por sexo (\%) }\end{array}$} & \multicolumn{2}{c}{$\begin{array}{c}\text { Proporção de defasados por } \\
\text { IDH para cada sexo (\%) }\end{array}$} \\
\hline IDH & homens & mulheres & homens & mulheres \\
\hline alto & 36,8 & 36,3 & 40,6 & 32 \\
\hline médio & 24,5 & 25,4 & 56,6 & 46 \\
\hline baixo & 38,7 & 38,3 & 68,4 & 54 \\
\hline total & 100 & 100 & 52,5 & 41,7 \\
\hline
\end{tabular}

Fonte: Microdados PNAD 2006

A tabela 4 possibilita a discussão da influência do trabalho sobre a defasagem. 
Amélia Artes e Marília Carvalho

Tabela 4

Defasagem idade/anos de estudo, por sexo e trabalho (10 a 14 anos)

\begin{tabular}{lcccc}
\hline & $\begin{array}{c}\text { Distribuição segundo o } \\
\text { trabalho de defasados } \\
\text { por sexo (\%) }\end{array}$ & $\begin{array}{c}\text { Proporção de defasados por } \\
\text { trabalho para cada sexo (\%) }\end{array}$ \\
\hline Trabalho & homens & mulheres & homens & mulheres \\
\hline Trabalha & 14,4 & 6,9 & 68,4 & 49,4 \\
\hline Não trabalha & 85,6 & 93,1 & 50,5 & 41,3 \\
\hline total & 100 & 100 & 52,5 & 41,7 \\
\hline
\end{tabular}

Fonte: Microdados PNAD 2006

Adverte-se que essa análise deve ser considerada como uma tendência, pois o grupo de trabalhadores da população em geral representa $11,1 \%$ dos meninos e 5,9\% das meninas. Porém, uma vez que o trabalho é invocado na literatura como a principal justificativa para a piora nos indicadores educacionais dos meninos, esses resultados descritivos podem ajudar na explicação da influência do trabalho sobre a defasagem, o que será complementado com as análises estatísticas apresentadas a seguir.

$\mathrm{O}$ índice de defasados aumenta significativamente para o grupo de trabalhadores. No conjunto da população em foco, $52,5 \%$ dos meninos e $41,7 \%$ das meninas estão defasados, enquanto no grupo de trabalhadores $e$ trabalhadoras esse índice sobe para $68,4 \%$ dos meninos e $49,4 \%$ das meninas. Em outro enfoque, tem-se um acréscimo de $30,3 \%^{8}$ pelo fator trabalho para os meninos e $18,5 \%^{9}$ para as meninas em seus índices de defasagens.

Portanto, é indiscutível que o trabalho aumenta a defasagem escolar. Mas como explicar que 50,5\% dos meninos e $41,3 \%$ das meninas que não trabalham também estão defasados? Por que o trabalho afeta significativamente mais os meninos do que as meninas? Outros elementos precisam ser colocados nessa

8 cálculo $68,4-52,5 / 52,5=30,3$

9 cálculo $49,4-41,7 / 41,7=18,5$ 
Defasagem escolar dos meninos no Brasil

equação para compreender a defasagem escolar dos jovens, de forma mais intensa entre os meninos, independentemente de trabalharem ou não.

A relação entre afazeres domésticos e defasagem escolar (tabela 5), aparentemente, é pouco significativa para o grupo dos meninos, já que sua situação apresenta uma variação de 46,4\% para $53,6 \%$, bem menor do que nos caso das meninas. Dentre as moças defasadas, $80,5 \%$ realizam afazeres domésticos.

\section{Tabela 5}

Defasagem idade/anos de estudo, por sexo e afazeres domésticos. (10 a 14 anos)

\begin{tabular}{lcccc}
\hline & \multicolumn{2}{c}{$\begin{array}{c}\text { Distribuição segundo } \\
\text { afazeres domésticos de } \\
\text { defasados por sexo (\%) }\end{array}$} & \multicolumn{2}{c}{$\begin{array}{c}\text { Proporção de defasados } \\
\text { por afazeres domésticos } \\
\text { para cada sexo (\%) }\end{array}$} \\
\hline Afazeres & homens & mulheres & homens & mulheres \\
\hline $\begin{array}{l}\text { Realiza } \\
\text { afazeres }\end{array}$ & 46,4 & 80,5 & 53,6 & 43,1 \\
\hline $\begin{array}{l}\text { Não realiza } \\
\text { afazeres }\end{array}$ & 53,6 & 19,5 & 51,6 & 37 \\
\hline Total & 100 & 100 & 52,5 & 41,7 \\
\hline
\end{tabular}

Fonte: Microdados PNAD 2006

Se o trabalho é um fator determinante para a compreensão da defasagem dos meninos, os afazeres domésticos constituem um diferencial importante para a compreensão da defasagem das meninas.

A tabela 6 complementa a informação anterior, desmembrando os afazeres domésticos pelo seu tempo de duração. Os índices obtidos apontam que $37 \%$ das meninas que não realizam afazeres domésticos estão defasadas. Essa proporção passa a $51,6 \%$, se considerado o universo de meninas que realizam mais de 20 horas de atividade, coincidentemente o mesmo índice de meninos defasados que não realizam afazeres domésticos. 
Amélia Artes e Marília Carvalho

Tabela 6

Defasagem idade/anos de estudo por sexo e tempo de duração de afazeres domésticos (10 a 14 anos)

\begin{tabular}{lcccc}
\hline & $\begin{array}{c}\text { Distribuição por duração } \\
\text { de afazeres de defasados } \\
\text { por sexo (\%) }\end{array}$ & $\begin{array}{c}\text { Proporção de defasados } \\
\text { por duração de afazeres } \\
\text { para cada sexo (\%) }\end{array}$ \\
\hline $\begin{array}{l}\text { Tempo de } \\
\text { duração }\end{array}$ & homens & mulheres & homens & mulheres \\
\hline $\begin{array}{l}\text { Não realiza } \\
\text { afazeres } \\
\text { domésticos }\end{array}$ & 53,6 & 19,5 & 51,6 & 37 \\
\hline 1 a 10 horas & 37,5 & 43,4 & 52,5 & 39,2 \\
\hline 11 a 20 horas & 7,1 & 24,3 & 58,2 & 47,1 \\
\hline $\begin{array}{l}21 \text { horas ou } \\
\text { mais }\end{array}$ & 1,4 & 12,9 & 58,7 & 51,6 \\
\hline total & 100 & 100 & 52,5 & 41,7 \\
\hline
\end{tabular}

Fonte: Microdados PNAD 2006

A tabela 7 apresenta $^{10}$ informações sobre a idade de ingresso no trabalho, considerando também idades inferiores ao grupo enfocado. A maior incidência, tanto para meninos quanto para meninas é a idade de 10 anos (colunas à esquerda). Nota-se que a idade predominante para os meninos ingressarem no trabalho é menor do que a idade média; no caso das meninas acontece o contrário, a maioria ingressa no trabalho após os 10 anos, faixa etária que coincide idealmente com a finalização do processo de alfabetização (de acordo com a nomenclatura atual, com a passagem do ensino fundamental I para o ensino fundamental II).

${ }^{10}$ As tabelas de 7 a 11 exploram as características do grupo de jovens trabalhadores. Vale lembrar que as primeiras duas colunas apresentam a porcentagem de defasados dentro da variável escolhida (idade, raça, afazeres domésticos, IDH e freqüência à escola), totalizando $100 \%$ da população considerada, isto é, jovens trabalhadores; a terceira e quarta colunas apresentam a porcentagem dentro da variável defasagem, não permitindo a totalização na vertical. Na última linha destas colunas, é apresentada a distribuição percentual de defasados segundo o sexo. 
Defasagem escolar dos meninos no Brasil

A defasagem no grupo que trabalha é maior do que a do grupo total, subindo de $52,5 \%$ para $68,4 \%$, entre os meninos, e de $41,7 \%$ para $49,4 \%$, entre as meninas.

Tabela 7

Porcentagem de idade de ingresso no trabalho por sexo, para o grupo que trabalha (4 a 14 anos)

\begin{tabular}{ccccc}
\hline & \multicolumn{2}{c}{$\begin{array}{c}\text { Distribuição etária de } \\
\text { ingresso no trabalho dos } \\
\text { defasados por sexo (\%) }\end{array}$} & \multicolumn{2}{c}{$\begin{array}{c}\text { Proporção de defasados } \\
\text { por faixa etária de ingresso } \\
\text { no trabalho por sexo (\%) }\end{array}$} \\
\hline Idade & homens & mulheres & homens & mulheres \\
\hline 4 anos & 0,1 & -- & 100 & -- \\
\hline 5 anos & 0,8 & 1,3 & 66,5 & 63 \\
\hline 6 anos & 1,8 & 2,6 & 63,8 & 83,1 \\
\hline 7 anos & 6,5 & 4 & 70,8 & 38,5 \\
\hline 8 anos & 13,1 & 11,3 & 72,3 & 58,2 \\
\hline 9 anos & 14,2 & 11,6 & 69,6 & 45,6 \\
\hline 10 anos & 26,4 & 28,2 & 71,6 & 55,4 \\
\hline 11 anos & 13 & 12 & 66.6 & 50,7 \\
\hline 12 anos & 12 & 13,6 & 69,2 & 45,5 \\
\hline 13 anos & 7,6 & 10,2 & 61,4 & 42,1 \\
\hline 14 anos & 4,5 & 5,3 & 53,7 & 39,3 \\
\hline & 100 & 100 & 68,4 & 49,4 \\
\hline
\end{tabular}

Fonte: Microdados PNAD 2006

Na tabela 8, acrescenta-se o elemento raça na apresentação do grupo que trabalha. O resultado é a presença de negros um pouco maior nesse grupo do que na população geral, sem diferença por sexo (colunas à esquerda). As colunas à direita demonstram que $76,3 \%$ dos meninos trabalhadores defasados são negros, índice $36 \%$ superior ao da população negra em geral. No caso das meninas negras, o fator trabalho aumenta em $6,8 \%$ a defasagem, considerado o grupo de mesma raça. Assim, o trabalho associado à raça prejudica mais os meninos. 
Amélia Artes e Marília Carvalho

Tabela 8

Defasagem idade/anos de estudo, por sexo e raça para o grupo que trabalha (10 a 14 anos)

\begin{tabular}{lcccc}
\hline & \multicolumn{2}{c}{$\begin{array}{c}\text { Distribuição dos defasados } \\
\text { por raça e sexo }(\%)\end{array}$} & \multicolumn{2}{c}{ Proporção de defasados por } \\
raça para cada sexo (\%)
\end{tabular}

Fonte: Microdados PNAD 2006

A tabela 9 apresenta informações relativas a afazeres domésticos para o grupo de jovens trabalhadores.

Tabela 9

Defasagem idade/anos de estudo, por sexo e tempo de duração dos afazeres para o grupo que trabalha

(10 a 14 anos)

\begin{tabular}{lcccc}
\hline & $\begin{array}{c}\text { Distribuição do tempo } \\
\text { de duraçáo dos afazeres } \\
\text { domésticos dos } \\
\text { defasados por sexo (\%) }\end{array}$ & $\begin{array}{c}\text { Proporção de defasados por } \\
\text { tempo de duração dos } \\
\text { afazeres domésticos para cada } \\
\text { sexo (\%) }\end{array}$ \\
\hline $\begin{array}{l}\text { Tempo de } \\
\text { duração }\end{array}$ & homens & mulheres & homens & mulheres \\
\hline $\begin{array}{l}\text { Não realiza } \\
\text { afazeres } \\
\text { domésticos }\end{array}$ & 42,4 & 8,9 & 67,3 & 45,1 \\
\hline 1 a 10 horas & 45,3 & 45,7 & 68 & 45,9 \\
\hline $\begin{array}{l}11 \text { a 20 } \\
\text { horas }\end{array}$ & 10 & 31,6 & 73,4 & 54,8 \\
\hline $\begin{array}{l}21 \text { horas ou } \\
\text { mais }\end{array}$ & 2,2 & 13,8 & 76,9 & 53,9 \\
\hline total & 100 & 100 & 68,4 & 49,4 \\
\hline Fonte: Microdados PNAD 2006 & & & \\
\hline
\end{tabular}


Defasagem escolar dos meninos no Brasil

A coluna à esquerda indica que boa parte dos meninos defasados não realiza afazeres domésticos. No caso das meninas, essa atividade faz parte da sua rotina e aumenta a defasagem: 45,4\% das meninas defasadas trabalham e assumem atividades domésticas por um período superior a 11 horas semanais.

A tabela 10, contendo informações a respeito da relação entre defasagem e IDH para o grupo que trabalha, aponta a existência de maior concentração de meninos e meninas defasados nas regiões de IDH baixo. Uma possível explicação pode ser as diferentes modalidades de trabalho desenvolvidas nessas regiões: atividades manuais que, ao exigir um maior esforço físico, dificultam ainda mais a frequência escolar. ${ }^{11}$

Tabela 10

Defasagem idade/anos de estudo, por sexo e IDH para o grupo que trabalha (10 a 14 anos)

\begin{tabular}{lcccc}
\hline & \multicolumn{2}{c}{$\begin{array}{c}\text { Distribuição segundo o IDH } \\
\text { de defasados por sexo (\%) }\end{array}$} & \multicolumn{2}{c}{ Proporção de defasados por } \\
IDH para cada sexo (\%)
\end{tabular}

Fonte: Microdados PNAD 2006

A associação entre trabalho, escola e defasagem (tabela 11) permite verificar que o trabalho não impossibilita a frequência escolar, porém aumenta o índice de defasagem. Considerando que $91,9 \%$ dos meninos trabalhadores e $95 \%$ das meninas trabalhadoras frequentam a escola, pode-se afirmar que a porcentagem de defasados aumenta proporcionalmente para ambos os sexos quando inseridos no trabalho.

${ }^{11}$ Como não se observam diferenças por sexo, essa questão não será explorada. 
Amélia Artes e Marília Carvalho

Tabela 11

Defasagem idade/anos de estudo, por sexo e frequência à escola para o grupo que trabalha (10 a 14 anos)

\begin{tabular}{lcccc}
\hline & $\begin{array}{c}\text { Distribuição da } \\
\text { frequência de defasados } \\
\text { por sexo (\%) }\end{array}$ & $\begin{array}{c}\text { Proporção de defasados por } \\
\text { frequência para cada sexo } \\
(\%)\end{array}$ \\
\hline $\begin{array}{l}\text { Frequência } \\
\text { à escola }\end{array}$ & homens & mulheres & homens & mulheres \\
\hline frequenta & 90,3 & 92,1 & 66,9 & 47,8 \\
\hline $\begin{array}{l}\text { Não } \\
\text { frequenta }\end{array}$ & 9,7 & 7,9 & 86,7 & 78,7 \\
\hline total & 100 & 100 & 68,4 & 49,4 \\
\hline Fonte: Microdados PNAD 2006 & & &
\end{tabular}

\section{Modelagem Estatística}

A análise descritiva apresentada anteriormente permite que se tenha uma idéia aproximada sobre o efeito das diferentes variáveis explicativas (sexo, raça, idade, IDH), quando aplicadas ao fator incidência de defasagem entre idade e anos de estudo.

No entanto, a análise apresentada tem algumas limitações. A mais importante é que o efeito das variáveis explicativas dessa incidência não leva em conta o perfil mais completo dos indivíduos. Somente é possível afirmar que o trabalho exerce algum efeito se comparamos indivíduos de perfis semelhantes que difiram, apenas, em sua condição de trabalhador. E isso só é viável utilizando-se uma análise estatística ${ }^{12}$, cujas técnicas permitem essa comparação de modo direto por meio dos modelos de regressão, que explica o comportamento esperado de uma variável dependente (por exemplo, a incidência da defasagem idade/anos de estudo), levando-se em conta um conjunto de variáveis independentes (por exemplo, sexo, raça, trabalho, etc.) (Corrar, 2007).

\footnotetext{
${ }^{12}$ Rinaldo Artes, doutor em estatística pela Universidade de São Paulo, trabalhou voluntariamente no apoio à pesquisa e na construção do modelo estatístico.
} 
Defasagem escolar dos meninos no Brasil

Nessa modelagem, foram consideradas as seguintes variáveis explicativas: sexo (masculino/feminino); raça (branca/ negra); IDH - unidade da federação de residência, classificada conforme descrito acima; horas semanais de trabalho; e horas semanais de afazeres domésticos.

Também é importante considerar eventuais efeitos de interação. Por exemplo, é possível que o fato de uma pessoa ser do sexo masculino ou de raça negra leve a um aumento de sua chance de defasagem. Nesse caso, há um efeito de interação entre sexo e raça.

Inicialmente, ajustou-se um modelo completo com efeitos de interação entre sexo $e$ as demais variáveis. A significância dos efeitos foi verificada por meio de testes de Wald: para que se chegasse a um modelo final, foram excluídos os efeitos de interação não significativos. A qualidade do ajuste foi verificada pelo teste de Hosmer e Lemeshow (2000).

Foram ajustados dois modelos: o primeiro comporta a categorização de tempo de trabalho e de afazeres domésticos, o segundo considera essas mesmas variáveis, mas sem a categorização. Pelo fato de se trabalhar com tempos categorizados, o primeiro modelo permite avaliar o efeito dessas variáveis sem a influência de eventuais valores discrepantes de tempo de trabalho ou de afazeres domésticos ${ }^{13}$ (ou seja, pessoas que gastam um tempo muito mais elevado do que as demais). $\mathrm{O}$ segundo modelo, além de confirmar os resultados do primeiro, permite a realização de análises mais detalhadas em relação a essas duas variáveis.

A tabela 12 apresenta a estimativa dos parâmetros, os respectivos erros-padrão, a estatística de Wald, seus graus de liberdade, os respectivos valores $\mathrm{P}$ e a estimativa da razão de chances, uma medida de risco de defasagem. O termo constante refere-se ao seguinte conjunto de caracteres: mulher, branca, residente em unidades da federação com IDH alto, que não

${ }^{13}$ Além disso, eventuais não linearidades são automaticamente acomodadas. 
Amélia Artes e Marilia Carvalho

trabalha e não tem afazeres domésticos. Os demais efeitos estabelecem diferenças em relação a esse perfil.

Tabela 12

Valores de significância da regressão logística

\begin{tabular}{|c|c|c|c|c|c|c|}
\hline & $\begin{array}{l}\text { Estima- } \\
\text { tiva }\end{array}$ & $\begin{array}{l}\text { Erro } \\
\text { padrão }\end{array}$ & Wald & $\begin{array}{l}\text { Grau de } \\
\text { liberdade }\end{array}$ & P. & $\begin{array}{l}\text { Razão } \\
\text { de } \\
\text { chance }\end{array}$ \\
\hline Homem & ,362 & ,040 & 82,738 & 1 & ,000 & 1,436 \\
\hline Raça & ,497 & ,032 & 243,010 & $\overline{1}$ & ,000 & 1,644 \\
\hline Homem negro &, 172 &, 045 & 14,837 & 1 & ,000 & 1,188 \\
\hline IDH & & & 273,466 & 2 & ,000 & \\
\hline Médio & ,401 & ,038 & 110,040 & 1 & ,000 & 1,493 \\
\hline baixo & ,591 & ,036 & 264,508 & 1 & ,000 & 1,806 \\
\hline Homem * IDH & & & 6,583 & 2 & ,037 & \\
\hline Homem Médio &,- 041 & ,054 & ,573 & 1 & ,449 & 960 \\
\hline Homem baixo & ,093 & ,051 & 3,295 & 1 & ,069 & 1,098 \\
\hline $\begin{array}{l}\text { Tempo de } \\
\text { trabalho }\end{array}$ & & & 15,882 & 3 & 001 & \\
\hline 1 a 10 horas & ,074 & ,094 & ,613 & 1 & ,434 & 1,076 \\
\hline 11 a 20 horas & ,343 & ,096 & 12,845 & 1 & ,000 & 1,409 \\
\hline $\begin{array}{l}21 \text { horas ou } \\
\text { mais }\end{array}$ & ,193 & ,113 & 2,910 & 1 & ,088 & 1,213 \\
\hline $\begin{array}{l}\text { Homem-tempo } \\
\text { de trabalho }\end{array}$ & & & 27,721 & 3 & ,000 & \\
\hline 1 a 10 horas & ,335 & ,125 & 7,108 & 1 & ,008 & 1,397 \\
\hline 11 a 20 horas & ,277 & ,122 & 5,180 & 1 & ,023 & 1,319 \\
\hline $\begin{array}{l}21 \text { horas ou } \\
\text { mais }\end{array}$ &, 587 & ,143 & 16,905 & 1 & ,000 & 1,799 \\
\hline $\begin{array}{l}\text { Tempo de } \\
\text { afazeres } \\
\text { domésticos: }\end{array}$ & & & 98,787 & 3 & ,000 & \\
\hline 1 a 10 horas & ,012 & ,024 & ,246 & 1 & ,620 & 1,012 \\
\hline 11 a 20 horas & ,222 & ,035 & 40,805 & 1 & ,000 & 1,248 \\
\hline $\begin{array}{l}21 \text { horas ou } \\
\text { mais }\end{array}$ & ,382 & ,049 & 62,028 & 1 & ,000 & 1,465 \\
\hline Constante &,- 982 & ,033 & 883,782 & 1 & ,000 & 374 \\
\hline
\end{tabular}


Defasagem escolar dos meninos no Brasil

Há efeito de tempo dos afazeres domésticos sobre a probabilidade de defasagem $(\mathrm{P}<0,000)$, quando controladas as outras variáveis. Porém, esse efeito só é perceptível para jornadas acima de 11 horas semanais. Ao comparar dois indivíduos iguais em todas as variáveis, exceto a do tempo de afazeres domésticos, no intervalo de 11 a 20 horas, o risco de apresentar defasagem escolar aumenta $24,8 \%$ em relação a quem não realiza afazeres domésticos e, no intervalo de 21 horas ou mais, o risco aumenta $46,5 \%$ em relação a quem não realiza (ver coluna Razão de Chances na tabela 12).

Ao considerar o tempo de trabalho e o sexo, foi detectada uma interação significativa $(\mathrm{P}<0,001)$. Para as mulheres, quando o tempo de trabalho é menor que 10 horas, não se encontrou diferença significativa na probabilidade esperada de defasagem escolar $(\mathrm{P}=0,434)$ frente às não trabalhadoras. Acima de 11 horas, contudo, estima-se que o risco de defasagem é 32,5\% maior do que o de uma mulher que não trabalha, mantendo-se as demais variáveis constantes. Observe-se que não houve diferença significativa na variação do risco quando consideradas mulheres que trabalharam de 11 a 20 horas ou mais de 20 horas.

Comparado a uma mulher que não trabalha, o homem apresenta um aumento escalonado no risco de defasagem escolar: $43,6 \%$ para homem que não trabalha, $116,2 \%{ }^{14}$ para homem que trabalha por um período de 1 a 10 horas, $167,0 \%{ }^{15}$ para homem que trabalha por um período de 11 a 20 horas, e $213,3 \%{ }^{16}$ para homem que trabalha por um período de 21 horas ou mais.

Analisando apenas o grupo de meninos trabalhadores, observa-se que, já no primeiro grupo (1 a 10 horas de trabalho), a chance de defasagem escolar mais que dobra, alcançando $116,2 \%$ e chegando a $213,3 \%$ para as jornadas de 21 horas ou mais. Contrastado o grupo de meninos trabalhadores ao das meninas

${ }_{14}$ cálculo $[\exp (0,362+0,074+0,335)=2,162]$
${ }^{15}$ cálculo $[\exp (0,362+0,343+0,277)=2,670]$
${ }^{16}$ cálculo $[\exp (0,362+0,193+0,587)=3,133]$ 
trabalhadoras, a grande diferença entre eles indica que, se o trabalho é um fator que aumenta a defasagem em ambos os sexos, o prejuízo é maior para os meninos.

É interessante observar o aumento do risco de defasagem escolar dos meninos que não trabalham em comparação ao das meninas que não trabalham, quando controladas as outras associações (ou seja, pessoas de perfil idêntico nas demais variáveis do modelo): o risco de defasagem aumenta 43,6\% (apenas pelo fato de ser "homem"). Isso permite concluir que outros fatores - para além de trabalho, afazeres domésticos, raça e IDH - prejudicam a escolarização dos meninos.

Da mesma forma, a interação entre IDH e sexo mostrou-se significativa $(\mathrm{P}=0,037)$. Mantidas as demais variáveis sob constância, em relação a uma mulher que mora em uma UF com IDH alto, o risco de defasagem aumenta em 49,3\% para mulher de região com IDH médio; 80,6\% para outra com IDH baixo; 40,6\% para homem de região com IDH alto; $105,9 \%{ }^{17}$ para homem com IDH médio; e 184,6 para homem com IDH baixo.

Esses resultados reforçam a tese de que a probabilidade de defasagem é influenciada pela situação econômica, medida pelo $\mathrm{IDH}$, e atinge diferentemente homens e mulheres. Quanto pior o IDH da região, maior o risco de defasagem escolar para ambos os sexos, porém, a comparação do risco para os mesmos IDH's indica que a defasagem é maior para os meninos, quando controladas as influências das outras variáveis. Dessa forma, podese alegar que apenas pelo fato de ser homem o risco de defasagem escolar aumenta $40,6 \%$ para os meninos.

$\mathrm{O}$ efeito de interação entre sexo e raça também se mostrou significativo $(\mathrm{P}<0,001)$. Mantidas as demais variáveis sob controle, o risco de defasagem em comparação à mulher branca aumenta em $64,4 \%$ para uma mulher negra; $43,6 \%$ para um homem branco; e $180,5 \%{ }^{18}$ para um homem negro.

${ }^{17}$ cálculo exp $(0,362+0401-0,041)=2,059$

18 cálculo $\exp [0,362+0,497+0,172)=2,805$ 
Defasagem escolar dos meninos no Brasil

Conforme verificado nas demais interações, o fator sexo também é determinante na compreensão desses resultados. Contrastando homens brancos e negros com mulheres brancas, observa-se que o risco de defasagem aumenta $43,6 \%$ para os homens, se controladas todas as outras variáveis. Entretanto, ao comparar o risco para grupos de mesma raça, os homens negros apresentam um risco três vezes maior de defasagem em comparação às mulheres negras.

Houve, ainda, efeito significativo para os afazeres domésticos $(\mathrm{P}<0,001)$. Mantidas as demais variáveis constantes, pode-se dizer que não há diferença significativa no risco de defasagem escolar, ao comparar pessoas que não têm afazeres domésticos com aquelas que as executam por um período de 1 a 10 horas $(\mathrm{P}=0,620)$. Confrontando as que não têm afazeres domésticos com as que têm por um período de 11 a 20 horas, o risco aumenta 24,8\%; no grupo que tem 20 horas ou mais de afazeres domésticos, em relação ao que não tem, o risco aumenta $46,5 \%$.

Como mencionado, uma segunda análise foi feita a fim de relacionar quantitativamente tempo de afazeres domésticos a tempo de trabalho. Por razões técnicas ${ }^{19}$, foram utilizadas como variáveis do modelo a raiz quadrada do tempo de trabalho e a raiz quadrada do tempo de afazeres domésticos.

A tabela 13 apresenta o ajuste desse modelo. Assim como no Modelo 1 foram consideradas significativas as interações entre sexo e trabalho $(\mathrm{P}<0,001)$, sexo e IDH $(\mathrm{P}=0,036)$ e sexo e raça $(\mathrm{P}<0,001)$, além de um novo efeito de interação: sexo e raiz quadrada do tempo de afazeres domésticos $(\mathrm{P}<0,001)$. O sinal negativo desse coeficiente leva-nos a concluir que o efeito de tempo de afazeres domésticos é mais prejudicial para mulheres do que para homens, caso haja probabilidade de a pessoa apresentar defasagem escolar. Isso ficará mais claro nas análises seguintes.

${ }^{19}$ Controle de fortes assimetrias das variáveis tempo de trabalho e tempo de afazeres domésticos. 
Amélia Artes e Marília Carvalho

Tabela 13

Análise da interação afazeres domésticos e trabalho como variáveis quantitativas (de 10 a 14 anos)

\begin{tabular}{lllclc}
\hline & $\begin{array}{l}\text { Erro } \\
\text { padrão }\end{array}$ & Wald & $\begin{array}{c}\text { Graus de } \\
\text { liberdade }\end{array}$ & $\mathrm{P}$ & $\begin{array}{c}\text { Razão de } \\
\text { chance }\end{array}$ \\
\hline Homem &, 045 & 109,093 & 1 &, 000 & 1,607 \\
\hline raça &, 032 & 230,786 & 1 &, 000 & 1,624 \\
\hline Homem negro &, 045 & 16,671 & 1 &, 000 & 1,200 \\
\hline $\mathrm{IDH}$ & & 271,502 & 2 &, 000 & \\
\hline médio &, 038 & 107,629 & 1 &, 000 & 1,487 \\
\hline alto &, 036 & 263,256 & 1 &, 000 & 1,804 \\
\hline Homem * IDH & & 6,644 & 2 &, 036 & \\
\hline Homem médio &, 054 &, 421 & 1 &, 516 &, 966 \\
\hline Homem alto &, 051 & 3,620 & 1 &, 057 & 1,102 \\
\hline $\begin{array}{l}\text { Raiz quadrada horas } \\
\text { trabalho }\end{array}$ &, 014 & 13,044 & 1 &, 000 & 1,053 \\
\hline $\begin{array}{l}\text { Homem: raiz } \\
\text { quadrada horas } \\
\text { trabalho }\end{array}$ &, 018 & 28,168 & 1 &, 000 & 1,101 \\
\hline $\begin{array}{l}\text { Raiz quadrada horas } \\
\text { "afazeres" }\end{array}$ &, 009 & 97,505 & 1 &, 000 & 1,093 \\
\hline $\begin{array}{l}\text { Homem: raiz } \\
\text { quadrada horas } \\
\text { "afazeres" }\end{array}$ &, 014 & 18,641 & 1 &, 000 &, 943 \\
\hline Constante &, 035 & 998,330 & 1 &, 000 &, 331 \\
\hline
\end{tabular}

Os gráficos 13a e 13b apresentam as probabilidades de defasagem previstas pelo Modelo 2, que estuda o efeito de tempo de afazeres domésticos, ao passo que os gráficos $13 \mathrm{c}$ e $13 \mathrm{~d}$ permitem avaliar o efeito do tempo de trabalho sobre essa probabilidade. 
Defasagem escolar dos meninos no Brasil

Gráfico 13a

Análise de afazeres domésticos como variável quantitativa, nos grupos branco e IDH alto (10 a 14 anos)

Probabilidade de defasagem para brancos, IDH

alto e não trabalham

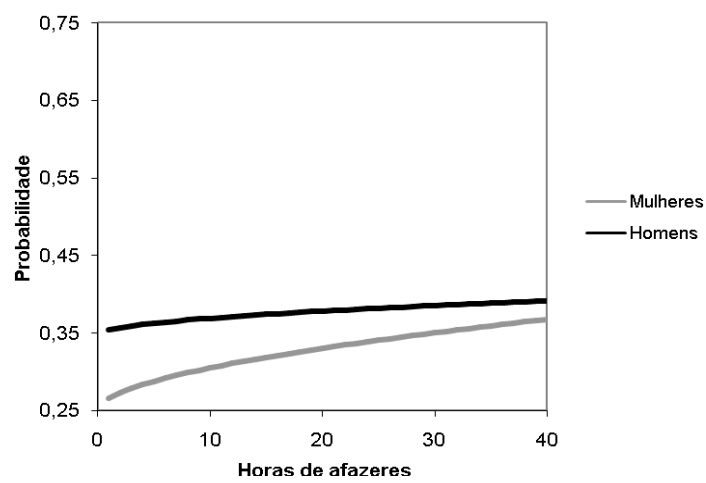

Fonte: Microdados PNAD 2006

\section{Gráfico 13b}

Análise de afazeres domésticos como variável quantitativa, nos grupos negro e IDH baixo (10 a 14 anos)

Probabilidade de defasagem para negros, IDH baixo e não trabalham

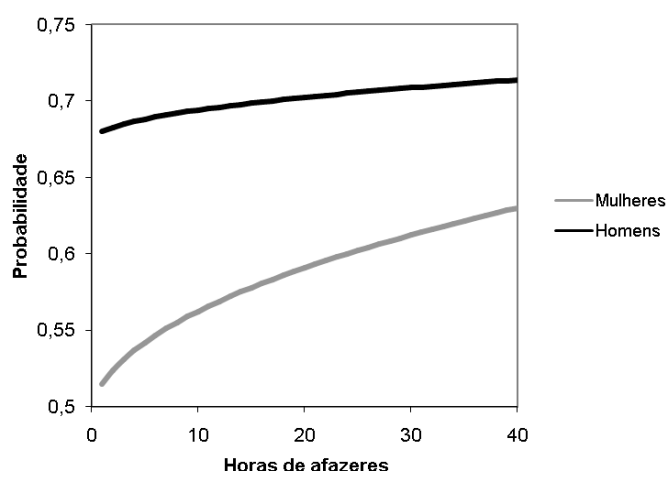

Fonte: Microdados PNAD 2006. 
No Gráfico 13a, a comparação proposta baseia-se em jovens do seguinte perfil: não trabalham, brancos e moradores em regiões de IDH alto, isto é, jovens nas melhores condições para minimizar o efeito da defasagem escolar; o gráfico $13 \mathrm{~b}$ apresenta a mesma situação, agora para o grupo de negros de regióes de IDH baixo. As curvas nos gráficos sugerem que, apesar da probabilidade de defasagem escolar ser inicialmente maior para os meninos sem afazeres domésticos, a curvatura para as meninas é mais acentuada, indicando que a atividade de afazeres domésticos prejudica mais as meninas do que os meninos. A probabilidade de defasagem para meninas brancas com 40 horas de afazeres domésticos aproxima-se ao valor inicial de probabilidade de defasagem para meninos sem afazeres (gráfico 13a) em Unidades da Federação de IDH alto. No gráfico 13b, observa-se o mesmo prejuízo para as meninas, o que pode ser visualizado na curvatura de defasagem. No caso dos meninos negros, a probabilidade de defasagem inicial já é alta, sendo que o fator afazeres domésticos não influencia intensamente. Por tratar-se de um grupo que não trabalha, os gráficos demonstram que há, além do trabalho, outros fatores prejudiciais aos meninos, principalmente aos negros, que apresentam uma alta probabilidade de defasagem escolar, apesar de não realizarem nenhuma das atividades analisadas.

Os gráficos 13c e 13d trazem à discussão o fator trabalho. 
Defasagem escolar dos meninos no Brasil

\section{Gráfico 13c}

Análise de trabalho como variável quantitativa, para os grupos branco e IDH alto (10 a 14 anos)

Probabilidade de defasagem para brancos, IDH alto e não afazeres

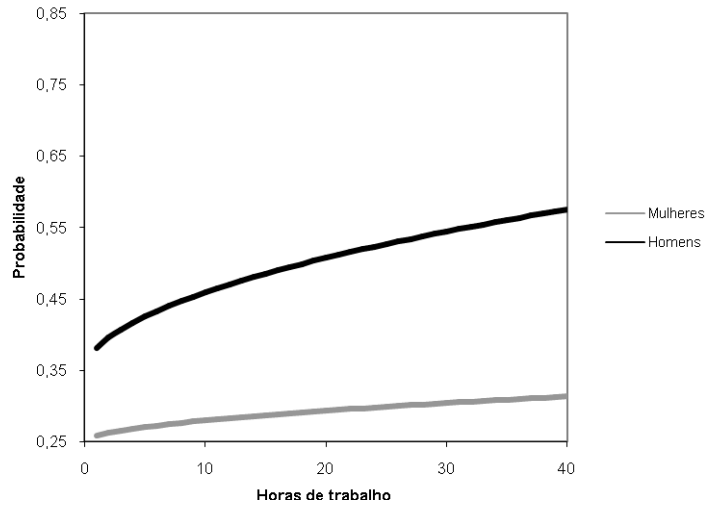

Fonte: Microdados PNAD 2006

Nesse caso, a curvatura maior é relativa aos meninos, indicando maior prejuízo para eles na probabilidade de defasagem escolar. A curvatura para as meninas indica uma pequena influência do trabalho no resultado da defasagem, havendo, principalmente, maior curvatura para as meninas negras (gráfico 13d) comparadas às brancas. 
Amélia Artes e Marília Carvalho

\section{Gráfico 13d}

Análise de trabalho, como variável quantitativa para os grupos negro e IDH baixo (10 a 14 anos)

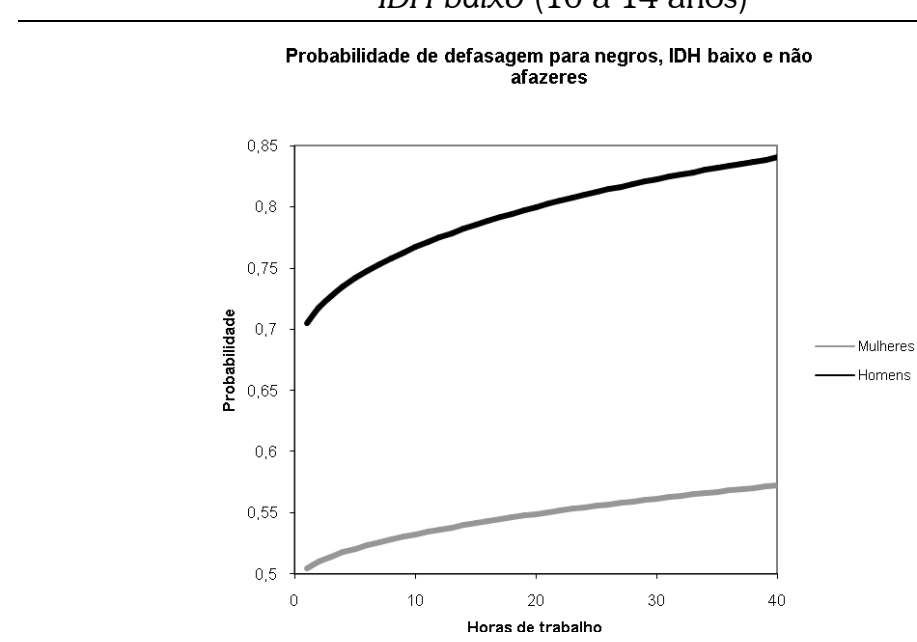

Fonte: Microdados PNAD 2006

Outro elemento importante a ser comentado é a distância entre as duas curvas. No caso de afazeres domésticos, as curvas tendiam à aproximação, isto é, a defasagem dos meninos é inicialmente maior, mas o fator afazeres domésticos prejudica mais as meninas e, portanto, a distância entre eles diminui. No caso do trabalho, como o prejuízo é maior para os meninos, a distância entre as curvas tende a aumentar. Na comparação por raça, os meninos negros apresentam as maiores probabilidades de defasagem escolar, reforçando, assim, a idéia de que o elemento raça é importante para a compreensão dos resultados.

A partir da modelagem é possível concluir, com certa margem de segurança, que o trabalho aumenta a defasagem escolar principalmente para os meninos; enquanto os afazeres domésticos influenciam a defasagem das meninas. Apesar de essas atividades funcionarem como agravantes, elas não podem ser consideradas como únicas explicações ou justificativas. Com o 
Defasagem escolar dos meninos no Brasil

controle das variáveis raça, IDH, afazeres domésticos e trabalho, se mantém a diferença entre meninos e meninas, demonstrando a necessidade de considerar outros elementos para a correta compreensão dessa defasagem.

\section{Meninos, educação e trabalho: como explicar?}

A análise descritiva dos dados já seria suficiente para desconstruir a tese de que o trabalho justifica o pior desempenho escolar dos meninos: se, por um lado, $11,1 \%$ dos meninos e $5,9 \%$ das meninas trabalham, por outro, $52,5 \%$ deles e $41,7 \%$ delas estão defasados. Isto é, grande parte da população de 10 a 14 anos está defasada nos estudos e apenas uma pequena parcela trabalha (embora o trabalho nessa faixa etária seja ilegal).

É certo que o fato de trabalhar aumenta a defasagem: no grupo que trabalha, $68,4 \%$ dos meninos e $49,4 \%$ das meninas estão defasados. Contudo, esse não pode ser considerado o único responsável pelas diferenças entre os percursos escolares de meninas e meninos. Esse resultado é reforçado pela análise regressiva que, ao explorar a questão do tempo de trabalho, aponta que quanto maior a jornada, maior o risco de defasagem para os meninos. Destaque-se que a defasagem é alta também no grupo que não trabalha e novamente mais acentuada entre os rapazes que entre as moças.

A análise dos afazeres domésticos indica que essa atividade é predominantemente feminina. No grupo analisado, 54,5\% dos meninos frente a $21,9 \%$ das meninas não realizam esta atividade. O tempo despendido nos afazeres domésticos aponta também resultados bastante desproporcionais entre os sexos: enquanto $8 \%$ dos rapazes realizam mais de 11 horas semanais, este índice chega a $32 \%$ para as meninas. Utilizando os resultados da modelagem, os dados revelam que as jornadas de afazeres domésticos, no período acima de 11 horas, aumentam o risco de defasagem escolar para as meninas. 
Porém, comparados os prejuízos para o percurso escolar, o dano causado pelo encargo de afazeres domésticos para o grupo das meninas é menor do que o causado pelo trabalho para os meninos. Por outro lado, cabe destacar que, na maior parte dos casos, os jovens de ambos os sexos conseguem conciliar a escola com o trabalho. $\mathrm{O}$ índice de frequencia escolar para o grupo que trabalha diminui de $97 \%$ (total da idade) para 92,4\% (grupo que trabalha) no caso dos meninos; e de $97,5 \%$ para $95,1 \%$ no caso das meninas. Assim, o fator trabalho atua de forma mais intensa para os meninos. Uma possível explicação, que não foi explorada neste estudo, é a existência de diferentes modalidades de trabalho realizadas por homens e mulheres.

Outro aspecto importante a ser ressaltado é a parcela de meninas que realiza afazeres domésticos, frequenta a escola $e$ ainda trabalha, vivenciando, portanto, uma tripla jornada. No grupo de defasadas, 91,3\% das meninas estão nessa categoria, contra $59,2 \%$ dos meninos.

Assim, a defasagem escolar - uma realidade presente no universo de meninos e meninas - está associada às atividades por eles desempenhadas, tanto no mundo do trabalho, como no dos afazeres domésticos, mas não necessariamente em uma relação linear de causa e efeito. Outros fatores influenciam essa situação e necessitam ser contextualizados.

No Brasil, a diferença por cor ou raça, polarizada em brancos e negros, influencia o desempenho escolar. Essa leitura construída por diferentes autores (Rosemberg, 2004, Beltrão 2002, Henriques, 2002; Hasenbalg, 1979) - também se confirmou neste estudo. Mas ressaltamos que a influência da cor ou raça sobre o desempenho escolar deve ser compreendida considerando também o sexo, lembrando que o maior prejuízo se refere ao sexo masculino. Na sociedade como um todo, a associação de sexo $e$ raça resulta numa opressão ainda maior para as mulheres negras, que se acentua caso sejam também pobres. Essa situação desprivilegiada é constatada em vários espaços sociais: mercado de trabalho, acesso a cargos de comando, representação política, 
Defasagem escolar dos meninos no Brasil

etc. Porém, na análise do percurso escolar dos jovens brasileiros, este estudo apontou que, em uma faixa etária específica e a partir de um indicador definido, as meninas negras apresentam melhores resultados comparativamente aos dos meninos, conforme outros autores já vinham indicando. Assim, na escolarização brasileira, os meninos pobres e negros são o grupo que mais enfrenta dificuldades. Se o fator raça está presente na caracterização dos piores resultados, esse fator afeta de maneira muito mais intensa o sexo masculino, levando-nos a buscar caracterizar quem são os meninos e rapazes em desvantagem no percurso escolar, de forma a evitar uma análise bipolar que tratasse o grupo de mulheres e o grupo de homens como homogêneos internamente e opostos entre si.

Compreender esse complexo quadro de dados empíricos exige igual sofisticação teórica. Talvez por isso, vários estudos, apesar de apresentar informações indicativas dessa inversão por sexo no campo educacional, privilegiem predominantemente as diferenças por raça e condição social, ignorando em suas análises um possível sucesso feminino.

De toda forma, a colcha de retalhos de variáveis que influenciam o desempenho diferenciado entre meninos e meninas precisa de novas possibilidades de explicação. Um caminho ainda pouco explorado no Brasil para essa compreensão é a análise das formas de masculinidade construídas internamente à sala de aula ou à escola, e mesmo em relação às diferentes expectativas das famílias para meninos e meninas. A escola, em especial, como um espaço de construção social, produz e reproduz concepções de masculinidade e feminilidade, diferentes conforme os pertencimentos raciais, seja pela ação dos/as profissionais da educação, seja pelas relações entre colegas. Como essas diferentes expectativas afetariam o desempenho escolar de meninos $e$ meninas, negros e brancos são questões ainda em aberto e que estão sendo pouco a pouco analisadas por estudos, em geral, de natureza qualitativa (Silva, 2004; Brito, 2006; Pereira, 2008; Rosemberg, 2004; Carvalho, 2003). 
Este artigo teve por objetivo confrontar o discurso majoritário que explica os problemas de desempenho constatados entre os meninos como consequencia de fatores externos à escola, em especial a inserção no mercado de trabalho. Os resultados apresentados pelas análises aqui desenvolvidas, por um lado, confirmam que, no caso do Brasil, os meninos se encontram em uma situação de maiores dificuldades em sua trajetória escolar, medida por meio da defasagem entre idade e anos de estudo. Por outro lado, quanto ao principal argumento utilizado para justificar esses piores resultados - a necessidade de inserir-se no mercado de trabalho - confirmou-se que é um fator, entre outros, que prejudica a escolarização dos rapazes e moças, aumentando as taxas de defasagem entre idade e anos de estudo, principalmente para os meninos negros de regiões mais pobres. Porém, como explicar que, de cada dez meninos, apenas um deles trabalha, enquanto cinco estão defasados? A compreensão desse fato requer que se enfrente a discussão sobre as masculinidades e se abra a caixa preta das relações intra-escolares, pois os fatores externos não são suficientes para explicá-lo.

\section{Referências bibliográficas}

Beltrão, Kaizô, Acesso à educação: diferenciais entre os sexos. Texto para Discussão 879, IPEA, 2002.

BRITO, Rosemeire. Santos. Intrincada trama de masculinidades $e$ feminilidades: fracasso escolar de meninos. Cadernos de Pesquisa, vol. 36, n 127, São Paulo, Fundação Carlos Chagas, 2006, pp.129149.

BRASIL. Pesquisa Nacional de Amostra de Domicílios - 2006. Notas Técnicas IBGE, 2006.

BRUSCHINI, Cristina Trabalho doméstico: inatividade econômica ou trabalho não remunerado. Revista Brasileira de Estudos Populacionais, vol. 23, nº 2, São Paulo, jul./dez. 2006, pp.331-353.

CARVAlHo, Marília Pinto de. Sucesso e fracasso escolar: uma questão de gênero. Educ. Pesquisa, vol. 29, nº 1, 2003 
Defasagem escolar dos meninos no Brasil

- Mau aluno, boa aluna? Como os professores avaliam meninos e meninas. Estudos feministas, vol.9, $\mathrm{n}^{\circ} 2$, Florianópolis, 2001, pp.554-574.

Estatísticas de desempenho escolar: o lado avesso. Educação e Sociedade, vol. 22, $\mathrm{n}^{\circ}$ 77, Campinas-SP, dez. 2001, pp.231-252.

. No coração da sala de aula: gênero e trabalho docente nas séries iniciais. São Paulo, Xamã/Fapesp, 1999.

CORRAR, Luiz J; PAULO, Edilson; DiAS FILHO, José Maria. Análise Multivariada: para cursos de administração, ciências contábeis e economia. São Paulo, Atlas/FIPECAFI, 2007.

Costa, Sérgio. A construção sociológica da raça no Brasil. Estudos Afroasiáticos, vol. 24, n 1, Rio de Janeiro, 2002, pp.35-61.

FERRARO, Alceu Ravenello. Gênero, raça e escolarização na Bahia e no Rio de Janeiro. Cadernos de Pesquisa, vol. 39, São Paulo, set./dez. 2009, pp.813-836.

. Gênero, cor/raça e escolarização nos Estados da Bahia e Rio de Janeiro: um experimento com base em micro dados do censo 2000. Reunião ANPED 30 anos, Caxambu-MG, 2007a.

Gênero, cor/raça e níveis de letramento em Santa Catarina e Alagoas: um experimento com micro dados do censo 2000. mimeo, $2007 b$.

. Género y alfabetización em el Brasil de 1940 al 2000: trazando la trayectoria de la relación. Anais da XVI ISA World Congress of Sociology, Durbam, South Africa, july, 2006, pp.23-29.

Hasenbalg, Carlos A. Discriminação e desigualdades raciais no Brasil. Rio de Janeiro, Graal, 1979.

HENRIQUES, Ricardo. Raça e Gênero no sistema de ensino: os limites das políticas universalistas na educação. UNESCO, 2002.

HIRATA, Helena. Divisão sexual do trabalho: o estado das artes. IN: HIRATA, Helena. Nova divisão sexual do trabalho? Um olhar voltado para a empresa e a sociedade. São Paulo, Boitempo, 2002. 
Amélia Artes e Marília Carvalho

HOSMER, David W.; LEMESHOW, Stanley. Applied logistic regression. $2^{\mathrm{a}}$ ed. New York, Wiley, 2000.

KASSOUF, Ana Lúcia. O que conhecemos sobre o trabalho infantil? Nova Economia, vol. 17, nº 2, Belo Horizonte, 2007, pp.323-350.

PEREIRA, Fábio Hoffmann. Encaminhamentos a Recuperação Paralela: Um Olhar de Gênero. Dissertação de mestrado, Faculdade de Educação/USP, 2008.

PINHEIRO, Luana et alii. Retrato das Desigualdades de gênero e raça. $3^{\text {a }}$ ed. Brasília, IPEA/SPM/UNIFEM, 2008.

ROCHA, Sônia. Trabalho precoce: realidade social e desafio de política pública. Nova Economia, vol. 13, $\mathrm{n}^{\circ}$ 2, Belo Horizonte, julho/ dezembro 2003, pp.61-80.

ROSEMBERG, Fúlvia e FREITAS, Rosangela. Participação de crianças brasileiras na força de trabalho e educação. Educação e Realidade, vol. 27, $\mathrm{n}^{\circ}$ 1, Porto Alegre, 2002, pp.95-126.

ROSEMBERG, Fúlvia. Desiguladades de raza y gênero em la sistema educativo brasileno. In: WINKLER, Donald y CUETO, Santiago. Etinicidad, raza, gênero y educacion em América Latina. Chile, PREAL, 2004.

. Educação Formal, mulheres e relações de gênero: balanço preliminar da década de 90. In: BRUSCHINI, Cristina e UNBEHAUM, Sandra. Gênero, democracia e sociedade brasileira. São Paulo, Fundação Carlos Chagas, 2002.

et alii. Mulher e educação formal no Brasil: estado da arte $e$ bibliografia. Brasília, INEP/REDUC, 1990.

SchWARTZMAN, Felipe; SchWARTZMAN, Simon. Tendências do trabalho infantil no Brasil - 1992-2002. Brasília, OIT, 2004.

ScotT, Joan W. Gênero: uma categoria útil de análise histórica. Educação \& Realidade, vol. 2, n 20, Porto Alegre, jul/dez de 1995, pp.71-100.

SILVA, Nelson Vale. Expansion escolar y estratificacion educacional en Brasil. In: WINKLER, Donald y CUETO, Santiago. Etinicidad, raza, gênero y educacion en América Latina. Chile, PREAL, 2004. 
Defasagem escolar dos meninos no Brasil

UNESCO. Relatório de Monitoramento Global de EPT 2003/2004 educação para todos; Gênero e educação para todos: o salto para a igualdade. São Paulo, Moderna, 2004. 